\title{
Incidence of lower limb amputation in diabetic patients between 2010 and 2018 in Osijek-Baranja County
}

\author{
(DSilvija Canecki- \\ Varžići, ${ }^{1,}$ \\ (DIvana Prpić- \\ Križevac $^{1,2 *}$ \\ University Hospital Centre \\ Osijek, Osijek, Croatia \\ ${ }^{2}$ Faculty of Medicine, Josip \\ Juraj Strossmayer University \\ of Osijek, Osijek, Croatia
}

\author{
KEYWORDS: lower limb amputation, diabetes mellitus, peripheral arterial disease. \\ CITATION: Cardiol Croat. 2019;14(9-10):243. | https://doi.org/10.15836/ccar2019.243 \\ *ADDRESS FOR CORRESPONDENCE: Ivana Prpić-Križevac, Klinički bolnički centar Osijek, Ul. Josipa Huttlera 4, HR- \\ 31000 0sijek, Croatia. / Phone: +385-91-5488-819 / E-mail: ipkrizevac@mefos.hr \\ ORCID:Silvija Canecki-Varžić, https://orcid.org/0000-0001-9535-7915 \\ Ivana Prpić-Križevac, https://orcid.org/0000-0003-4124-4426
}

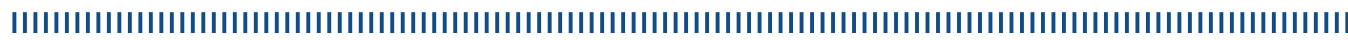

Introduction: Diabetic foot ulceration (DFU) is associated with high morbidity, mortality, and represents the leading cause of hospitalization in patients with diabetes. Peripheral arterial disease (PAD), present in half of patients with DFU, is an independent predictor of lower limb amputation (LLA) and can be difficult to diagnose in a diabetic population. Underdiagnosis and undertreatment of critical PAD are frequent. ${ }^{1-3} \mathrm{To}$ our knowledge there is no data about LLA incidence in Croatia neither in diabetics nor in nondiabetics. Our aim was to determine the incidence of amputation in patients with diabetes mellitus in Osijek-Baranja County. Patients and Methods: This was a tertiary-care-based retrospective study involving adult patients in whom amputation were performed for reasons relating to complication of PAD and/or diabetes in the University Hospital Centre Osijek from $1^{\text {st }}$ January 2008 to $31^{\text {st }}$ December 2018. We calculated LLA rates using estimates of the population with diabetes derived from CroDiab registry and Croatian Institute for Public Health for Osijek-Baranja County. LLAs were further categorized by level of amputation as follows: minor (toe and foot) and major (above foot and below knee, and above knee).

Results: There were 1551 LLAs in ten-year period. Smaller proportion of amputation was above foot (49.3\% vs 59.3\%). LLA rates per 1,000 adults with diabetes decreased 29\% between 2010 and 2013 and then increased 76 \% between 2014 and 2018 (Figure 1). We observed the same pattern in both minor and major LLA but rates of amputation above knee steadily increased 2.65 times between 2010 and 2018 (from 0.69 to 1.83 LLA per 1,000 patients).

Conclusion: This study confirmed high rate of lower limb amputation in diabetic patients in OsijekBaranja County which is representative for east Croatia region. After a decline of low limb amputations in diabetic patients between 2011 and 2013, LLA rates began to increase from 2014 to 2018. Reasons for that reversal trend are unclear. It can be due to poor management of CVD risk factors, poor glycemic control, and failure in early detection of PAD. It is also possible that change in health policy and organization of diabetes care together with socioeconomic factors could affect trends of LLA. Incidence rate of LLA in our population is important for further improvements in diabetes care and for decisions in health policy.

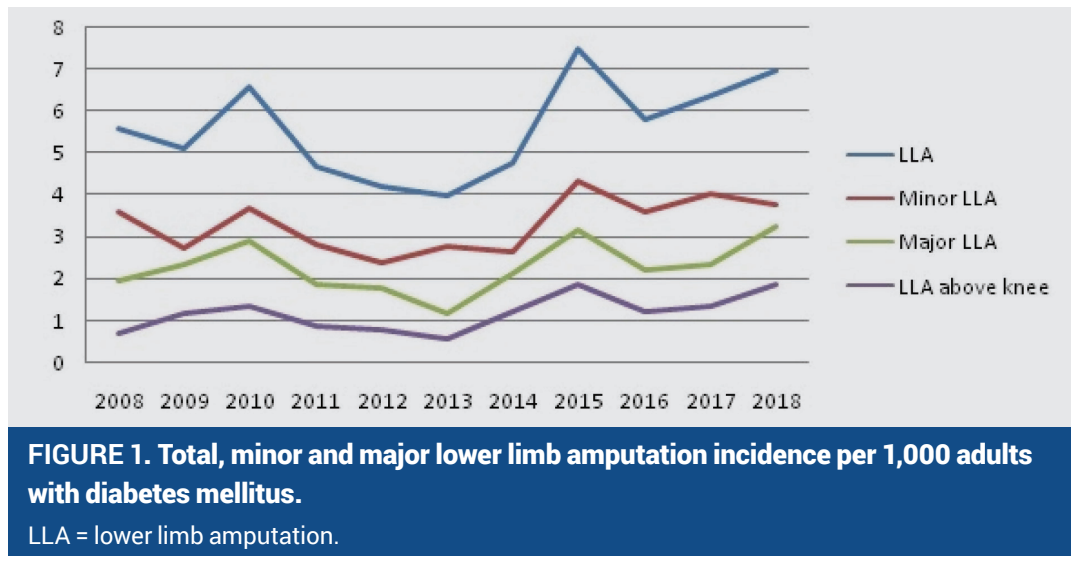

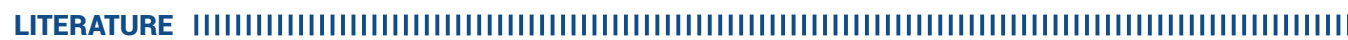

1. Geiss LS, Li Y, Hora I, Albright A, Rolka D, Gregg EW. Resurgence of Diabetes-Related Nontraumatic Lower-Extremity Amputation in the Young and Middle-Aged Adult U.S. Population. Diabetes Care. 2019 Jan;42(1):50-54. https://doi.org/10.2337/dc18-1380

2. Mohammedi K, Woodward M, Hirakawa Y, Zoungas S, Colagiuri S, Hamet P, et al; ADVANCE Collaborative Group. Presentations of major peripheral arterial disease and risk of major outcomes in patients with type 2 diabetes: results from the ADVANCE-ON study. Cardiovasc Diabetol. 2016 Sep 2;15(1):129. https://doi.org/10.1186/s12933-016-0446-x

3. Mustapha J, Gray W, Martinsen BJ, Bolduan RW, Adams GL, Ansel G, et al. One-Year Results of the LIBERTY 360 Study: Evaluation of Acute and Midterm Clinical Outcomes of Peripheral Endovascular Device Interventions. J Endovasc Ther. 2019 Apr;26(2):143-154. https://doi.org/10.1177/1526602819827295 